\title{
DEMANDA POTENCIAL POR UM CURSO DE NUTRIÇÃO E CONHECIMENTO SOBRE A PROFISSÃO POR ALUNOS DE ESTABELECIMENTOS DE ENSINO DE $2^{\circ}$ GRAU DE PIRACICABA,SP.
}

\author{
A.M.H. OMETTO; M.C.O. FURTUOSO; M.A.P. PIPITONE; M.V. da SILVA; G.L. STURION \\ Departamento de Economia Doméstica - ESALQ/USP - C.P. 9 - CEP: 13418-900 - Piracicaba,SP.
}

RESUMO: $O$ universo da pesquisa foi formado por alunos dos estabelecimentos de ensino da rede páblica e privada da cidade de Piracicaba, S.P. Foram levantadas informações sobre a opção profissional dos estudantes, o conhecimento do conteído dos cursos de nutriçăo e locais de atuação profissional. Os resultados da pesquisa revelaram a existência de uma substancial demanda potencial por um curso de nutrição a ser oferecido por uma universidade pública, preferencialmente localizada no interior do Estado de Sáo Paulo.

Descritores: nutrição, atuação profissional, demanda de alunos.

\section{POTENTIAL DEMAND FOR A COURSE ON NUTRITION AND KNOWLEDGE ABOUT THIS PROFESSION BY HIGH SCHOOL STUDENTS OF PIRACICABA,SP.}

\begin{abstract}
The research universe was the set of all high school students, both in public and private schools, in the city of Piracicaba, S.P. The survey yielded information on the professional preference of the students and their knowledge about the contents of an undergraduate course on nutrition and the types of professional activity. The results show that there is a substancial potential demand for a undergraduate nutrition course to be offered by a public university, preferably situated outside the state capital.
\end{abstract}

Key Worda: nutrition, professional activity, student demand.

\section{INTRODUÇÃO}

A Escola Superior de Agricultura "Luiz de Queiroz" oferece, atualmente, vagas para os cursos de Engenharia Agronômica e Engenharia Florestal e estuda a possibilidade de implementação de novos cursos de graduação. Entre as propostas que se apresentam ganha corpo a que prevê a criação de um curso superior de Nutrição.

Tal proposta justifica-se por várias razões, entre as quais pode-se destacar a estreita vinculação do objeto de estudo de um curso de nutrição e de uma escola de agronomia, que se dedicam, ainda que através de abordagens diferentes, ao estudo do alimento e sua relação com o homem.

Dada a proximidade entre objetos de estudo, a ESALQ acumulou uma estrutura em termos de docentes, instalações laboratoriais, bibliotecas, núcleos de pesquisa e um elenco de disciplinas oferecidas nos vários departamentos que são de interesse na formação do nutricionista.

Além disso, o Departamento de Economia Doméstica da ESALQ, autor da proposta de criação do Curso de Graduação em Nutrição, tem ampla experiência no ensino e pesquisa na área de nutrição e alimentos, como comprovam o número de disciplinas ligadas a esta área $\mathrm{e}$ já oferecidas pelo departamento, docentes aptos $e$ titulados, laboratórios especializados, pesquisas e convênios realizados, cursos extra-curriculares oferecidos, todos indicativos da capacitação departamental para o desenvolvimento das áreas de concentração do curso de nutrição.

A implantação de um curso de Nutrição na ESALQ poderá também contribuir ao aprimoramento da própria formação dos alunos do curso de agronomia, através do oferecimento de disciplinas de interesse comum às duas carreiras.

Uma análise da relação candidato/vagas nos últimos vestibulares realizados pela FUVEST (Fundação para o Vestibular do Estado de São Paulo) evidencia um crescente interesse pela carreira de nutrição, registrando no Vestibular de 1991 , a procura de 21,8 candidatos por vaga, o que colocou esta opção entre os doze cursos mais cotados. 
Segundo informações veiculadas por AMORIM (1990), então o presidente do Sindicato de Nutricionistas de São Paulo, a absorção deste profissional pelo mercado de trabalho é de praticamente $100 \%$, admitindo que se houvesse maior demanda neste mercado a oferta seria insuficiente. AMORIM (1970) ainda atribui o desemprego existente ao fato da maioria dos nutricionistas se concentrar nas grandes cidades.

Pesquisa realizada por BOOG et al., sobre a situação profissional dos Nutricionistas egressos da PUCCAMP (Pontifícia Universidade Católica de Campinas) nos anos de 1982 a 1986, revelou um índice de desemprego de apenas $2,4 \%$.

Uma análise da oferta de emprego para Nutricionistas aferida nos cadernos de emprego dos principais jornais do Estado de São Paulo revela a significativa procura por este profissional, indicando, assim, a existência de um quadro favorável à implantação de um novo curso na área.

\section{OBJETIVOS}

A partir destas informações acerca da situação profissional do nutricionista partiu-se, no âmbito desta pesquisa, para a identificação de qual é o interesse dos alunos de $2^{\circ}$ grau por um curso de nutrição que venha a ser oferecido no Campus da ESALQ.

Objetivou-se, também, com a presente pesquisa à avaliação do grau de conhecimento dos alunos de $2^{\circ}$ grau, possíveis candidatos ao curso em questão, a respeito da profissão de Nutrição.

\section{METODOLOGIA}

$O$ universo da pesquisa foi formado por alunos dos estabelecimentos de ensino da rede pública e privada da cidade de Piracicaba, situada a $170 \mathrm{Km}$ de São Paulo-Capital.

Para atingir os objetivos propostos, elaborou-se um questionário que visava coletar informações sobre a opção de carreira na decisão quanto ao curso de $3^{\circ}$ grau do estudante, os conhecimentos relativos à profissão do Nutricionista e grau de interesse manifestado em relação à implantação de um curso de nutrição na ESALQ.

Inicialmente foi realizado um pré-teste, para detectar possíveis dificuldades. Esse pré-teste consistiu na aplicação do questionário em uma classe, composta de 35 alunos, de uma escola pública central da cidade de Piracicaba.
A população objeto de estudo foi formada pelos estudantes de $2^{\circ}$ grau do período diurno dos colégios da rede pública e privada da zona urbana do município de Piracicaba e por alunos dos cursos preparatórios para o vestibular implantados na cidade.

\section{A amostra constou:}

- da totalidade dos alunos de uma classe de $2^{\circ}$ colegial e de $3^{\circ}$ colegial de cada escola, classes estas escolhidas aleatoriamente, resultando num total de $59 \%$ e $47 \%$ dos alunos destas séries matriculados nas escolas públicas e particulares, respectivamente.

- da totalidade dos alunos matriculados nos cursos preparatórios para o vestibular em funcionamento na cidade de Piracicaba.

Portanto, pode-se afirmar que em relação aos Cursos Pré-Vestibulares foi realizado um censo entre os alunos.

A opção pela aplicação do questionário na totalidade dos alunos de classes escolhidas, aleatoriamente, ao invés de um sorteio de um número determinado de estudantes por classe ligou-se a razões de ordem prática, como por exemplo: consulta prévia realizada junto a alguns diretores dessas escolas que indicou ser esta a melhor forma para evitar prejuízos de perda de aula aos alunos selecionados, ou o risco da não devolução de questionários, ou ainda respostas não fidedignas apresentadas pelo estudante, quando respondidas fora do estabelecimento de ensino.

Cabe salientar que tanto no "Colégio Anglo" como no "Colégio Luiz de Queiroz" a amostra englobou duas classes de $2^{\circ}$ e $3^{\circ}$ colegial por estarem estas agrupadas no dia da aplicação do questionário.

Os estabelecimentos de ensino da rede pública estadual foram selecionados a partir de uma listagem fornecida pela Delegacia de Ensino Regional de Piracicaba.

As TABELAS 1 e 2 apresentam a relação de estabelecimentos de ensino da rede pública e privada de Piracicaba que oferecem o curso colegial, com seus respectivos números de classes em funcionamento e de alunos por classe.

Pode-se observar que a grande maioria das escolas da rede pública contava com apenas uma classe de $2^{\circ}$ colegial e $3^{\circ}$ colegial, o que fez 
TABELA 1 - Relação de escolas da Rede Pública que oferecem Curso Colegial na cidade de Piracicaba,SP, 1990.

\begin{tabular}{|c|c|c|c|c|c|}
\hline & J. Coury & J. Gallo & S. Minucci & M. Moraes & F.F. Costa \\
\hline \multicolumn{6}{|l|}{$1^{\circ}$ Colegial } \\
\hline \multicolumn{6}{|l|}{ População } \\
\hline$N^{\circ}$ classes & - & - & -- & -- & 1 \\
\hline $\mathrm{N}^{0}$ aluno/classe & -- & -- & -- & -- & 25 \\
\hline \multicolumn{6}{|l|}{ Amostra } \\
\hline $\mathrm{N}^{0}$ classes & -- & -- & -- & -- & 1 \\
\hline $\mathrm{N}^{0}$ aluno/classe & -- & -- & - & - & 25 \\
\hline \multicolumn{6}{|l|}{$2^{\circ}$ Colegial } \\
\hline \multicolumn{6}{|l|}{ População } \\
\hline$N^{0}$ classes & 1 & 1 & 1 & 3 & 1 \\
\hline $\mathrm{N}^{0}$ aluno/classe & 35 & 40 & 36 & 35 & 9 \\
\hline \multicolumn{6}{|l|}{ Amostra } \\
\hline $\mathrm{N}^{0}$ classes & 1 & 1 & 1 & 1 & 1 \\
\hline $\mathrm{N}^{0}$ aluno/classe & 26 & 38 & 29 & 28 & 9 \\
\hline \multicolumn{6}{|l|}{$3^{\circ}$ Colegial } \\
\hline \multicolumn{6}{|l|}{ População } \\
\hline$N^{0}$ classes & 1 & 1 & 1 & 2 & -- \\
\hline $\mathrm{N}^{0}$ aluno/classe & 23 & 12 & 36 & 35 & -- \\
\hline \multicolumn{6}{|l|}{ Amostra } \\
\hline $\mathrm{N}^{\circ}$ classes & 1 & 1 & 1 & 2 & - \\
\hline $\mathrm{N}^{0}$ aluno/classe & 16 & 12 & 31 & 28 & -- \\
\hline
\end{tabular}

com que os resultados, praticamente, se configurassem num censo realizado entre estas escolas. Já nas escolas da rede privada o mesmo não se verifica, pois tais escolas dispunham de maior número de classes em cada ano.

Foi excluída a participação de alunos do $1^{\circ}$ colegial por considerar que os mesmos podem estar ainda indefinidos em relação à escolha de uma futura carreira profissional.

Uma ressalva deve ser feita à Escola Estadual de $1^{\circ}$ e $2^{\circ}$ graus "Fernando Febeliano da Costa", que embora contasse com um Curso 
Técnico de Nutrição, recentemente criado, não dispunha, ainda, de alunos de $3^{\circ}$ colegial. Neste caso optou- se por incluir na amostra o $1^{\circ}$ colegial. Cabe salientar que os questionários foram aplicados por dois entrevistadores, previamente treinados, durante a segunda quinzena de agosto no ano letivo de 1990.

\section{RESULTADOS E DISCUSSÃO}

Quando questionados sobre a intenção de ingressar em uma faculdade, a maioria dos interessados $(99,5 \%)$ respondeu afirmativamente. Destes, $67,0 \%$ já se decidiram por um determinado curso $c$ os outros $32,5 \%$ apresentavam-se indecisos.

TABELA 2 - Relação de escolas da Rede Privada com Curso Colegial na cidade de Piracicaba,SP, 1990.

D. Boseo Anglo L. de Queiroz

\section{$\underline{2^{\circ} \text { Colegial }}$}

\section{População}

$\mathrm{N}^{\circ}$ classes

$N^{0}$ aluno/classe

4
45

$50^{2}$

\section{Amostra}

$\mathrm{N}^{\circ}$ classes

$\mathrm{N}^{0}$ aluno/classe

$\begin{array}{ccc}1 & 2 & 1 \\ 35 & 43 / 36 & 36\end{array}$

\section{$\underline{3^{\circ} \text { Colegial }}$}

\section{População}

$\mathrm{N}^{\circ}$ classes

$\mathrm{N}^{\circ}$ aluno/classe

3
45

2

50

\begin{tabular}{lrrc} 
Amostra & & & \\
$\mathrm{N}^{0}$ classes & 1 & 1 & 2 \\
$\mathrm{~N}^{0}$ aluno/classe & 44 & 42 & $33 / 36$ \\
\hline
\end{tabular}

Ao se analisar separadamente as respostas dos alunos do terceiro colegial e cursos pré-vestibulares, verifica-se que o número de indecisos decai para $18,7 \%$. Estes dados indicam que a maior parte dos alunos indecisos são de segundo colegial.
Os 14 cursos mais citados pelos alunos que já haviam optado por uma carreira são, em ordem decrescente de preferência: Medicina, Agronomia, Odontologia, Administração, Computação, Medicina Veterinária, Engenharia Mecânica, Direito, Nutrição, Arquitetura, Engenharia Elétrica, Publicidade e Propaganda e Engenharia Química.

É importante destacar que o curso de Nutrição encontra-se entre os dez mais citados. Esta tendência vem confirmar os dados divulgados pela FUVEST sobre o total de inscritos por carreira com secundário completo, em 1991, que revelam estar a carreira de Nutrição em $9^{\circ}$ lugar na lista de preferência dos alunos, conforme demonstrado na TABELA 3.

TABELA 3 - Número de candidatos inscritos por vaga, com secundário completo, na FUVEST, 1991.

\begin{tabular}{|c|c|}
\hline Nome do Curso & $\mathrm{N}^{\circ}$ de inscritos/vaga \\
\hline Publicidade e Propaganda.. & 88,8 \\
\hline Jornalismo.................... & 49,0 \\
\hline Odontologia... & 30,7 \\
\hline Relações Públicas......... & $\ldots \ldots 26,0$ \\
\hline Administração............. & $\ldots \quad 25,8$ \\
\hline Medicina Veterinária..... & 25,7 \\
\hline Psicologia........................ & 25,5 \\
\hline Direito........................ & 23,8 \\
\hline Nutrição......................... & 21,8 \\
\hline Medicina e Ciências Biomé & as.............. 21,3 \\
\hline
\end{tabular}

Os dados desta pesquisa evidenciam, também, que ocorre uma demanda regional diferenciada da apresentada pela FUVEST. Tal situação parece refletir que o interesse dos alunos se concentra, preferencialmente, entre cursos estabelecidos na cidade de Piracicaba, e Região, como é o caso das preferências manifestadas por Engenharia Agronômica (Campus USP/Piracicaba), Odontologia (UNICAMP/Piracicaba) e Medicina (UNESP/Botucatu e UNICAMP/Campinas). Por esta interpretação é possivel inferir que a instalação de um Curso de Nutrição na ESALQ deverá aumentar, significativamente, a demanda por esta carreira na Região.

As respostas apresentadas pelos estudantes que ainda estão em dúvida quanto à 
carreira, mas que citaram as opções de cursos sobre os quais possivelmente recairia a sua escolha, revelam que as quatro primeiras opções são semelhantes às dos alunos já decididos, embora em ordem diferente, acrescidas da escolha de Nutrição, que aparece em primeiro lugar. (TABELA 4).

TABELA 4 - Número de estudantes indecisos quanto à escolha de curso na cidade de Piracicaba,SP. 1990.

\begin{tabular}{|c|c|c|}
\hline Nome do Curso & Percentu & $1 \%$ \\
\hline Nutrição........ & & 7,5 \\
\hline Odontologia... & & 6,2 \\
\hline Agronomia..... & & 5,6 \\
\hline Medicina.......... & & 5,3 \\
\hline Administração... & & 4,5 \\
\hline Psicologia........ & & 3,3 \\
\hline Computação..... & & 3,2 \\
\hline Engenharia Civil & & 2,9 \\
\hline Medicina Veterin & & 2,9 \\
\hline Ciências Contábe & & 2,7 \\
\hline Direito............. & & 2,4 \\
\hline
\end{tabular}

Objetivando verificar o grau de conhecimento dos alunos sobre a carreira de Nutrição, foram incluidas questões referentes ao conteúdo curricular dos cursos de nutrição, campo de atuação e atividades desenvolvidas pelos profissionais da área. Observa-se que apenas $4,8 \%$ dos jovens afirmaram desconhecer o conteúdo de um curso de nutrição, e, outros $6 \%$ não responderam. No entanto entre os $88 \%$ que descreveram o que se estuda nos Cursos de Nutrição as principais respostas recairam sobre:

$\left.1^{\circ}\right)$ Estudo dos Nutrientes $(39,4 \%$ das respostas).

$2^{\circ}$ ) Dietas Alimentares $(34,5 \%)$.

$3^{\circ}$ ) Estudo do Alimento $(32,7 \%)$.

$4^{\circ}$ ) Disciplinas na Área de Biológicas $(15,5)$.

$\left.5^{\circ}\right)$ Nutrição (11\%).

$6^{\circ}$ ) Administração de Serviços de Alimentação $(5,9 \%)$.

As respostas apresentadas atestam que os alunos detêm algumas informações acerca do objeto de estudo da formação do nutricionista. Segundo IPIRANGA (1990), a formação acadêmica do nutricionista leva-o "à compreensão do homem enquanto ser biológico (disciplinas da área básica - morfologia, psicologia, fisiopatologia) e social (Psicologia, Economia, Sociologia, Educação), do alimento, em sua natureza e processos do transformação (composição e tecnologia de alimentos, técnicas dietéticas) e da relação homem/alimento (a chamada nutrição aplicada a populações ou nutrição social)"

Quanto ao conhecimento accrca do campo de atuação do nutricionista, apontam para $58,9 \%$ de respostas de estudantes que demonstram conhecer onde trabalham os nutricionistas e $41 \%$ alegam não saber. Entre os que demonstram conhecer o campo de atuação do nutricionista. constatou-se o que se segue:

$\left.1^{\circ}\right) 41,3 \%$ - Trabalho em Empresas.

$2^{\circ}$ ) $38,4 \%$ - Prefeituras, Merenda Escolar.

Creches

$\left.3^{\circ}\right)$ 31,1\% - Hospitais c Ambulatórios.

$\left.4^{\circ}\right) 27,1 \%$ - Restaurantes Industriais

$\left.5^{\circ}\right) 11,3 \%$ - Indústria de Alimentos.

$\left.6^{\circ}\right) 11,1 \%$ - Clínicas, Consultórios e Academıs

Com base nesses resultados pode-se ressaltar que os alunos dispõem de informações sobre os locais de trabalho dos nutricionistas Deve-se destacar as respostas que especificam " órgão empregador e respectivos programas por eles desenvolvidos, como por excmplo: $38,4 \%$ dc respostas mencionando Prefeituras, os Programas de Merenda Escolar e Creches.

Quando os estudantes foram questionados sobre o conhecimento que os mesmos têm sobre "o que faz o profissional de Nutrição". os resultados obtidos mostram que $43,2 \%$ dos alunos alegam conhecer a atuação profissional do nutricionista, enquanto que outros $54,5 \%$ responderam de forma negativa.

Entre o grupo de alunos que respondeu, afirmativamente, o resultado é o que se encontra na (TABELA 5).

As respostas obtidas revelam conhecimento das atividades desenvolvidas pelos nutricionistas, pois correspondem às atividades previstas nos artigos citados na LEI No $8-234$ de 17 de setembro de 1991. (D.O $\mathrm{N}^{\circ} 181 \mathrm{de}$ 18/09/1991 - Brasília, DF), que regulamenta a profissão de nutrição.

Pode-se constatar que as referidas respostas relacionam a atuação do profissional, principalmente à administração de serviços de 
alimentação (TABELA 5). Esta constatação coincide com a significativa oferta de empregos na área, divulgada pelos cadernos especiais dos jornais Folha de São Paulo e Estado de São Paulo.

TABELA 5 - Áreas mencionadas de atuação do nutricionista apontadas pelos alunos da rede pública e privada da cidade de Piracicaba,SP. 1990.

\begin{tabular}{cll}
\hline Porcentagem & Área de Atuação do Nutricionista \\
\hline $58,5 \%$ & $\begin{array}{l}\text { Planejamento e Preparo de } \\
\text { Refeições (Administração de } \\
\text { Serviços de Alimentação) }\end{array}$ & $\begin{array}{l}\text { Dietas para regime de } \\
\text { emagrecimento (Dietoterapia) }\end{array}$ \\
$15,3 \%$ & $\begin{array}{l}\text { Controle de Qualidade dos } \\
\text { Alimentos e Estudo dos Alimentos }\end{array}$ \\
$10,9 \%$ & Educação Alimentar \\
\hline
\end{tabular}

Entre as opções de qualificação da profissão de Nutricionista, $76,6 \%$ consideram-na importante e necessária, $44,3 \%$ acreditam que o mercado está em expansão e 4,7 acham que o profissional da área "ganha bem". Por outro lado, $24,2 \%$ consideram que a profissão oferece poucas opções de emprego e outros $15 \%$ taxaram-na de "mal remunerada".

Sobre a questão salarial, PRADO \& ABREU apresentam dados relativos à remuneração de nutricionistas do Estado do Rio de Janeiro. Os autores concluíram que, em média, o nutricionista é contratado para trabalhar 36,8 horas por semana e recebe, por isso, o equivalente a 7,5 salários mínimos por mês (salário bruto), o que corresponde a 6,3 Salários Mínimos por 30 horas semanais de trabalho. Os autores ressaltam que este valor está abaixo dos 10 salários mínimos pelas mesmas 30 horas semanais de acordo com o piso salarial aprovado em 1986.

De uma maneira geral, quando são avaliados os atributos relativos à profissão de nutrição apresentados pelos entrevistados identifica-se um saldo bastante favorável à iniciativa de criação de um Curso de Graduação junto ao Campus da USP desta cidade.
Os entrevistados que, quando questionados sobre o interesse em optar por prestar vestibular e cursar uma escola de nutrição apresentaram respostas negativas, foram justamente os alunos que ou já optaram por outros cursos, ou aqueles que embora não tenham feito a opção mencionaram preferências por cursos de outras áreas do conhecimento.

As respostas afirmativas se referiam, principalmente, ao "interesse pela área de alimentos" (18,7\% das respostas), por julgar à "importância da área" (6,8\% das respostas) e ao "interesse pela área de biológicas" (2,9\% das respostas).

Estas mesmas respostas apontam para um interesse pelo Curso que parece atrair um número considerável de jovens $(32,6 \%)$, além de evidenciar que não há rejeição por parte dos mesmos a um Curso de Nutrição.

Dos alunos que demonstraram interesse nesta carreira a maioria justifica essa opção tendo em vista uma formação que privilegie a área de alimentos. A esse respeito cabe salientar que a instalação de um curso de nutrição junto a ESALQ seguramente atenderá esse interesse manifestado pelos entrevistados, uma vez que a Universidade oferece um ampliado conjunto de recursos humanos e materiais relacionados à citada área.

Cabe lembrar, também, que as entrevistas realizaram-se através de questionário composto por duas partes: a primeira referiu-se a dados gerais sobre a profissão do Nutricionista e a segunda destinou-se somente aos estudantes que na primeira parte responderam, afirmativamente, que cursariam uma Faculdade de Nutrição. Desse modo a segunda parte do questionário foi respondida por $28 \%$ do total de entrevistados.

Destes alunos entrevistados, $34,4 \%$ responderam que têm preferência por algum curso específico, sendo as seguintes Faculdades mais citadas: USP $(26,4 \%)$, UNICAMP $(3,3 \%)$, UNIMEP $(2,9 \%)$, PUCCAMP $(2,5 \%)$, Universidades Federais $(2,10 \%)$ e Universidades Estaduais $(1,6 \%)$.

A preferência por estudar em uma Faculdade ou Universidade Pública na Capital ou interior também foi muito clara: $91,5 \%$ dos alunos optaram por estudar na cidade de Piracicaba, contra 7,1\% na Capital do Estado de São Paulo. Esta escolha foi justificada por $76,4 \%$ dos entrevistados que afirmaram já residir em Piracicaba. 
Vale ressaltar que o questionário incluiu uma pergunta sobre qual a área da nutrição que o candidato em potencial escolheria para atuar. As respostas são as que se seguem: $66,3 \%$ dos intrevistados manifestaram preferência pela atuação em Indústrias de Alimentos; 26,89\% em Secretarias de Agricultura e Abastecimento; $18,48 \%$ em Restaurantes Industriais; $15,9 \%$ em Creches e Programas de Merenda Escolar e 14,2\% em alimentação Hospitalar (Dietoterapia).

\section{CONCLUSÃO}

De acordo com objetivos desta pesquisa pode-se concluir que, considerando o universo de alunos de $2^{\circ}$ grau da cidade de Piracicaba, existe um real interesse por um Curso de Nutrição a ser criado junto ao Campus da ESALQ/Universidade de São Paulo. A esse respeito deve-se acrescentar que os alunos também apresentaram interesse pelos cursos já oferecidos pelas Universidades públicas instaladas na região. Isto nos leva a acreditar que, uma vez instalado o curso de Nutrição na ESALQ, o mesmo atrairá uma demanda de alunos considerada "regional" ou seja, aquela que é composta por alunos que "não querem sair de perto da cidade para estudar". Pesquisas veiculadas por jornais e Revistas diversas têm mostrado que esta é uma tendência que se consolida em função da crise econômica e dos altos custos envolvidos na manutenção dos jovens fora de casa para realizar seus estudos.

Outra informação bastante favorável apresentada pela pesquisa é a que demonstra não haver rejeição quanto ao curso de Nutrição. Neste sentido, a FUVEST tem mostrado que o interesse dos candidatos por esta carreira tem se elevado de forma constante e gradual.

A pesquisa permitiu também concluir que os alunos do $2^{\circ}$ grau da Cidade de Piracicaba têm conhecimento razoável acerca da profissão e áreas de atuação do Nutricionista o que evidencia que este profissional já consolidou seu papel na sociedade.
Dados como os aferidos por esta pesquisa, apresentam-se úteis não só por apontar informações positivas quanto à existência de uma considerável demanda potencial por um curso de nutrição que poderia ser criado junto à ESALQ/USP, bem como por demonstrar preferências quanto às áreas de atuação do nutricionista que correspondem, em termos gerais, aquelas áreas que potencialmente devem ser enfatizadas num curso de Nutrição instalado junto a ESALQ, tais como as de: administração de serviços de alimentação e ciência dos alimentos.

\section{REFERÊNCIAS BIBLIOGRÁFICAS}

AMORIM, L. Cozinha Industrial, $\mathbf{n}^{\circ}$ 9, Ano II, 1990, p.29-32.

BOOG, M.C.F. e outros. Situação Profíssional dos Nutricionistas Egressos da PUCCAMP em Revista de Nutrição da PUCCAMP, Vol. $1, n^{\circ} 2$, julho a dezembro de 1988, p.139-152.

PIRANGA, L. Delimitaçâo do objeto de trabalho do Nutricionista: Subsídios para uma discussão. Saúde em Debate, Londrina, PR. CEDES, $n^{\circ}$ 29. p.62-69. 1990.

PRADO, S.D. \& ABREU, M.S.D. Nutricionista: onde trabalha? Quais suas condições de Trabalho. Revista Nutrição, PUCCAMP, Campinas, 4 (1/2):65-92, jan/dez, 1991.

Enviado para publicação em 08.03 .93

Aceito para publicação em 28.04 .93 